\title{
Spinal reflexes as indicator of motor preparation in man
}

\author{
C. H. M. BRUNIA and F. M. VUISTER \\ Tilburg University, Tilburg, The Netherlands
}

\begin{abstract}
During the fixed foreperiod $(4 \mathrm{sec})$ of two reaction time experiments, using 80 subjects, Hoffman reflexes were simultaneously evoked in both legs in a pseudorandom order at 13 different measuring points. The purpose of the study was to investigate the time course of amplitude changes in both legs, in muscles both involved and not involved in the response. In Experiment 1, subjects responded after the imperative signal by a plantar flexion of either the right or left foot. Thus, reflexes were evoked via the motoneuron pool relevant for the response and via the contralateral irrelevant pool. In Experiment 2, subjects pressed a button with either the right or the left index finger. Thus, reflexes were evoked via motoneurons, irrelevant for the response. Reflex amplitudes during the foreperiod were larger than during the intertrial interval (ITI). An early increase was found at $100-200 \mathrm{msec}$ after the warning signal. Thereafter, amplitudes decreased but remained larger than during the ITI. After 1,000 msec, a steady increase was found, with the largest amplitudes near the end of the foreperiod. Amplitude changes were not different for relevant and irrelevant muscles. It was concluded that the second increase might be part of a motor preparation process.
\end{abstract}

Preparation for a movement can be investigated in reaction time experiments with a fixed interstimulus interval (ISI) between a warning stimulus (WS) and the response stimulus (RS). The use of WS causes a shortening of the mean reaction time (RT). The improved performance implies an earlier discharge of the motoneurons that innervate the muscles used in responding.

The excitability of these motoneurons can be estimated by means of monosynaptic reflexes evoked via the same motoneuron pool before the movement is made (Gerilowsky \& Tsekov, 1975; Requin, 1969). In general, changes in amplitude indicate changes in the output of the motoneuron pool, and consequently they are an index of fluctuations in (1) motoneuron excitability and (2) presynaptic inhibition of the Ia fibers, which conduct the afferent volley to the motoneuron pool (Figure 1). Evoking reflexes during an ISI provides the opportunity to study specific and nonspecific changes in the excitability of the motoneurons. Changes are specific when they are present exclusively in the muscle that is to respond. They are nonspecific when both involved and noninvolved muscles show the same reaction pattern. It is obvious that at a certain moment between stimulus and response, the specific activation has to be

This work is part of a program supported by the Dutch Organisation for the Advancement of Basic Research ZWO (Grant 58-44), the Dutch Health Organisation TNO (CLEO), and the Esther Evrard Fund. The computer program for the LAB 8E was developed by Hans Adriaanse and Henk van Nieuwstadt. Lied Damman assisted in the experiments, which were carried out in the Dr. Hans Berger Clinic at Breda. Han Brunia and Loes Verhallen assisted in the data analysis.
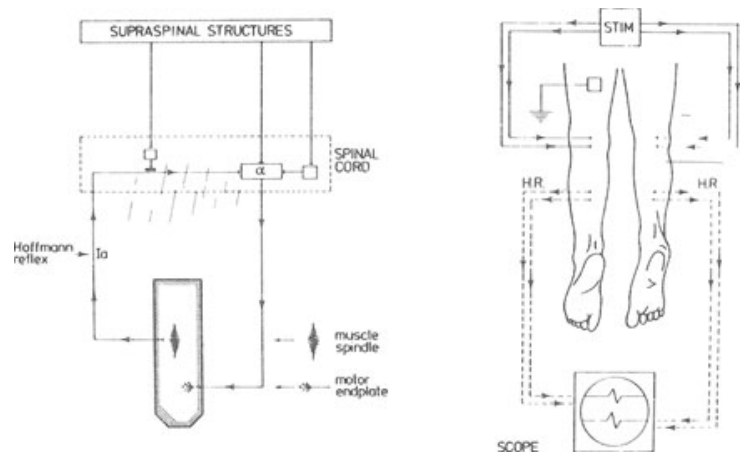

Figure 1. (Right) Schematic representation of the experimental setup. $H$ reflexes are evoked by means of electrical stimulation of the Ia afferents of the tibial nerve in the popliteal fossa. (Left) Simplified diagram of the nervous structures involved in $H$ reflexes. Of the peripheral afferents, only Ia fibers from the muscle are indicated; on the spinal level, most connections are omitted as well. Alpha motoneurons are facilitated or inhibited, directly or via interneurons, from peripheral and central areas. The indicated supraspinal pathways may be facilitatory or inhibitory. Only presynaptic inhibition is indicated by a heavy line.

present, because a response implies only one welldefined muscle action. If the response has to be made by finger movements, reflexes evoked in the legs are necessarily nonspecific (although they might be of importance).

To study specific aspects of motor preparation, subjects were instructed to make a plantar flexion of the foot as quickly as possible after the RS. For this movement, the calf muscle (triceps surae) is used. Reflexes can be evoked in these muscles by an electrical stimulation of the Ia afferent fibers of the tibial nerve in the popliteal fossa (Figure 1). 
In the two experiments to be presented, these socalled Hoffmann $(\mathrm{H})$ reflexes were evoked simultaneously in both legs at different moments of the ISI. In Experiment 1, the response had to be given by either one of both legs. This provides the opportunity to study simultaneously the time course of changes in the output of motoneuron pools, both those involved and those not involved in the response. Until now only ISIs of $1 \mathrm{sec}$ have been investigated (Gerilowski \& Tsekov, 1975; Mitchie, Clarke, Sinden, \& Glue, 1975; Requin, 1969; Requin, Bonnet, \& Semjen, 1977; Semjen, Bonnet, \& Requin, 1973). In Experiment 2, the response had to be made by finger movements. Although the $\mathrm{H}$ reflex in this case cannot provide an indication of a specific motor preparation process, because the motoneuron pools on the lumbar level are presumably of no importance for the cervical level, the reflex amplitude could serve as a control, as neither leg is involved in the task. A comparable experiment was done by Papakostopoulos and Cooper (1973). Their subjects responded with the left hand after a 2-sec ISI while EEGs were recorded simultaneously.

Because clear indications of motor preparation have been found in studies on the contingent negative variation (CNV) using an ISI of longer duration than the classic $1 \mathrm{sec}$ (Gaillard, 1978; Loveless, 1977; Loveless \& Sanford, 1974; Rohrbaugh, Syndulko, \& Lindsley, 1976), it was decided to study reflex amplitude changes during an ISI of $4 \mathrm{sec}$. Comparable experiments, using the same interval and foot responses, were run to study motor preparation on the cortical level by CNV techniques (Brunia, 1980).

\section{METHOD}

Subjects were seated comfortably in a specially devised chair with supports for head, arms, and legs. The feet were carefully fixed to a footpedal, which could not be moved on the noninvolved side. On the involved side, a plantar flexion could be made with the distal part of the footpedal. Constant-current square waves of $1 \mathrm{msec}$ were applied transcutaneously by a Simon electrode to the tibial nerve in the popliteal fossa in order to evoke $\mathrm{H}$ reflexes. The anode was placed proximal to the knee. The current strength was adjusted to make a small direct motor response visible during the whole experiment. H reflex amplitudes were between $50 \%$ and maximum value. For each subject, as much as possible, reflex amplitudes of comparable size were evoked in both legs. Reflexes were recorded by means of $\mathrm{Ag}-\mathrm{AgCl}$ electrodes, attached $4 \mathrm{~cm}$ apart to the triceps surae muscle. Peakto-peak amplitudes were measured on line by the A/D converter of a DEC Lab 8E computer. Presentation of a tone as WS, of a light as RS, and the triggering of the stimulation equipment were monitored by the computer.

Each 4-sec ISI was followed by an ITI of $16 \mathrm{sec}$. Reflexes were evoked 10 times, in random order, at each of 13 different temporal measuring points during the ISI: $100,200,300,500$, $1,000,1,500,2,000,2,500,3,000,3,500,3,700,3,800$, and $3,900 \mathrm{msec}$ after the WS. During each ITI, reflexes were evoked at random between 6 and $10 \mathrm{sec}$ after the RS. For each subject, means and standard deviations were calculated per ISI measuring point. The ITI data per subject were taken together and considered one point. The values of the 13 different measuring points were expressed as a percentage of the mean ITI level.
In Experiment 1, the subjects were instructed to make a plantar flexion with one foot immediately after the presentation of the RS. In Experiment 2, they pressed a button with the index finger. Each experiment consisted of two conditions. In Experiment 1, half of the subjects had to respond with the right foot, the other half with the left. The data of the involved leg from both conditons were taken together, as were those of the noninvolved leg. In Experiment 2, half of the subjects had to use the right hand, the other half the left. The data on the right leg in both conditons were taken together, as were those of the left leg. Each condition was performed by 20 subjects of both sexes, ranging in age from 18 to 25 years.

A two-factor analysis of variance (ANOVA) on "involvedness" and "measuring points" with repeated measurements was carried out on the scores of Experiment 1. A similar ANOVA was carried out on the data of Experiment 2, the factors being "left-right" and "measuring points." Separate ANOVAs were carried out on the data of the 1st second and the last $3 \mathrm{sec}$, separately.

\section{RESULTS}

Mean amplitudes during the ISI were larger than during the ITI in both experiments (Figures 2 and 3). The main effect "involvedness" was not significant in Experiment 1, in contrast to the main effect "mea-

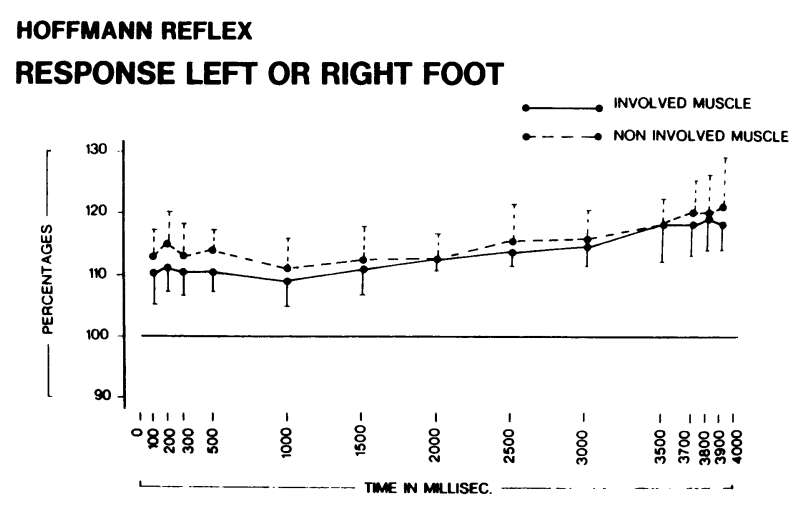

Figure 2. Experiment 1: Mean amplitudes of $\mathbf{H}$ reflexes, evoked in involved and noninvolved muscles at 13 different measuring points of a 4-sec ISI. The reflexes recorded during the ITI per subject are taken as control $(=100 \%)$. Data from 40 subjects are averaged. Vertical lines indicate the $95 \%$ level of confidence. Note that the ISI amplitudes are larger than the mean ITI level.

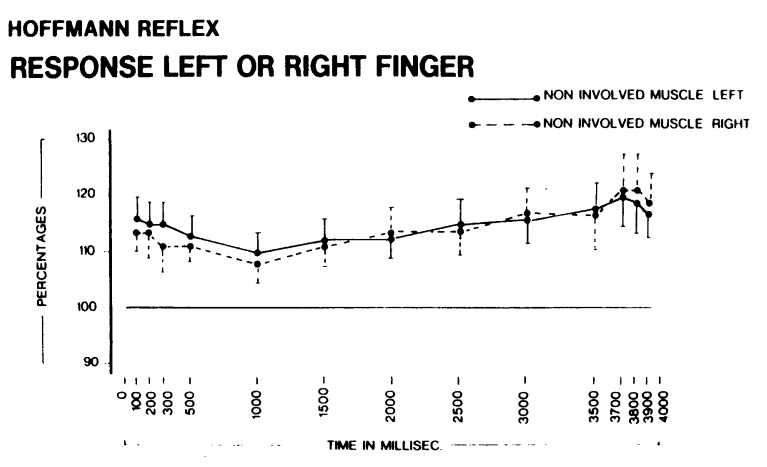

Figure 3. Experiment 2: Mean amplitudes of $\mathbf{H}$ reflexes, evoked in noninvolved muscles. The reflexes recorded during the ITI per subject are taken as control $(=100 \%)$. Data of 40 subjects are averaged. Vertical lines indicate the $95 \%$ level of confidence. Note that the ISI amplitudes are larger than the mean ITI level. 
Table 1

ANOVAs on H-Reflexes Evoked During 4-Sec Foreperiod (80 Subjects)

\begin{tabular}{|c|c|c|c|c|c|c|}
\hline & \multicolumn{2}{|c|}{ Complete ISI } & \multicolumn{2}{|c|}{ First Second of ISI } & \multicolumn{2}{|c|}{ Last Second of ISI } \\
\hline & df & $\mathbf{F}$ & df & $\mathrm{F}$ & df & $\mathrm{F}$ \\
\hline & \multicolumn{6}{|c|}{ Response: Right or Left Foot (40 Subjects) } \\
\hline $\begin{array}{l}\text { Involvedness } \\
\text { Measuring Points } \\
\text { Involvedness by Measuring Points }\end{array}$ & $\begin{array}{r}1,39 \\
12,468 \\
12,468\end{array}$ & $\begin{array}{c}1.570 \\
10.400 \dagger \\
.556\end{array}$ & $\begin{array}{r}1,39 \\
4,156 \\
4,156\end{array}$ & $\begin{array}{r}2.896 \\
.920 \\
.095\end{array}$ & $\begin{array}{r}1,39 \\
8,312 \\
8,312\end{array}$ & $\begin{array}{c}1.223 \\
12.352 \dagger \\
.793\end{array}$ \\
\hline Involvedness by Measuring Points & \multicolumn{6}{|c|}{ Response: Right or Left Hand (40 Subjects) } \\
\hline $\begin{array}{l}\text { Right-Left } \\
\text { Measuring Points } \\
\text { Right-Left by Measuring Points }\end{array}$ & $\begin{array}{r}1,39 \\
12,468 \\
12,468\end{array}$ & $\begin{array}{l}.266 \\
9.184 \dagger \\
1.496\end{array}$ & $\begin{array}{r}1,39 \\
4,156 \\
4,156\end{array}$ & $\begin{array}{l}3.492 \\
4.076^{*} \\
.437\end{array}$ & $\begin{array}{r}1,39 \\
8,312 \\
8,312\end{array}$ & $\begin{array}{r}.003 \\
12.708 \dagger \\
.829\end{array}$ \\
\hline
\end{tabular}

${ }^{*} p<.001 . \quad t p<.0001$.

Table 2

Wilcoxon Matched Pairs Signed-Ranks Test

\begin{tabular}{|c|c|c|c|c|c|c|c|c|c|c|c|}
\hline \multicolumn{6}{|c|}{ Experiment 1} & \multicolumn{6}{|c|}{ Experiment 2} \\
\hline \multicolumn{3}{|c|}{ Involved Muscle } & \multicolumn{3}{|c|}{ Noninvolved Muscle } & \multicolumn{3}{|c|}{ Right Muscle } & \multicolumn{3}{|c|}{ Left Muscle } \\
\hline \multicolumn{2}{|c|}{ Milliseconds } & \multirow{2}{*}{$\frac{z}{.54 \dagger \dagger}$} & \multicolumn{2}{|c|}{ Milliseconds } & \multirow{2}{*}{$\frac{\mathrm{z}}{1.28 t \dagger}$} & \multicolumn{2}{|c|}{ Milliseconds } & \multirow{2}{*}{$\frac{\mathrm{z}}{2.52 *}$} & \multicolumn{2}{|c|}{ Milliseconds } & \multirow{2}{*}{$\frac{z}{2.60 *}$} \\
\hline 100 & 1000 & & 100 & 1000 & & 100 & 1000 & & 100 & 1000 & \\
\hline 200 & 1000 & $2.11 * *$ & 200 & 1000 & $2.14 * *$ & 200 & 1000 & $2.59 *$ & 200 & 1000 & $2.23 * *$ \\
\hline 1000 & 3700 & $4.16 \dagger$ & 1000 & 3700 & $4.01 \dagger$ & 1000 & 3700 & $5.22 \dagger$ & 1000 & 3700 & $3.75 \dagger$ \\
\hline 1000 & 3900 & $4.29 \dagger$ & 1000 & 3900 & $4.93 \dagger$ & 1000 & 3900 & $4.55 \dagger$ & 1000 & 3900 & $3.13 \dagger$ \\
\hline
\end{tabular}

${ }^{*} p<.01 . \quad{ }^{* *} p<.02 . \quad t p<.0001 . \quad$ t†Nonsignificant.

suring points." No significant interaction was found (Table 1). In Experiment 2, the main effect "leftright" was not significant as distinct from the main effect "measuring points." The interaction again was not significant (Table 1). Essentially the same results were found with ANOVAs of the 1st second and the last $3 \mathrm{sec}$ of the ISI. In both experiments, the smallest amplitudes were found at $1,000 \mathrm{msec}$. This implies the existence of an early and a late increase in reflex amplitudes. A Wilcoxon matchedpairs signed ranks test was performed on the data at 100 and $200 \mathrm{msec}$ after the WS and at $1,000 \mathrm{msec}$ in Experiments 1 and 2. The same was done with the data at $1,000 \mathrm{msec}$ after the WS and at 3,700 and 3,900 msec, respectively (Table 2 ).

\section{DISCUSSION}

$\mathrm{H}$ reflex amplitudes are larger during the ISI than during the ITI. It seems to be of no importance whether or not the response is carried out on the cervical or the lumbar level: $H$ reflex amplitudes increase in both experiments in a comparable way. This points to an aspecific activation of the motoneuron pools. In the course of the ISI, smallest amplitudes are found at $1,000 \mathrm{msec}$, but they remain above the ITI level. An early increase in amplitude is present shortly after the WS, a late increase before the presentation of RS. The early increase has been reported by Requin et al. (1977), who studied H reflexes during an ISI of $1 \mathrm{sec}$. An increase of $\mathrm{H}$ reflex amplitudes after presentation of a tone has also been found by Mellvill Jones, Watt, and Rossignol (1973); the knee jerk shows a similar increase after an auditory stimulus (Beale, 1971). In the latter case, no motor response was given. Davis and Beaton (1968) report a differential effect of tones of different intensity, the stronger stimulus being followed by larger reflex amplitudes. Because, in Experiment 2, the early increase is also present, it seems reasonable to conclude that this rise is related to the WS rather than to the RS.

Gottlieb and Agarwal (1973a) have noted the strong similarity between early facilitation after an audiovisual stimulus and the facilitation observed in the active limb during voluntary contraction. In contrast, we seem to be confronted with two different processes. One is an increase of amplitudes, due to an audiospinal facilitation of the motoneuron pool (Mellvill Jones et al., 1973), and the other is an increase due to motor preparation. Gottlieb and Agarwal's (1973a) experiment does not allow discrimination between the two processes, because their audio-visual signal is followed immediately by a voluntary movement. In other words, they make their subjects perform a RT experiment without a foreperiod. A RT experiment with a foreperiod (ISI) provides a better possibility to study motor preparation. If the length of the ISI is sufficient, discrimination between the two processes becomes possible, since they maintain a different time course.

It has been argued for some time that it is not facilitation, but inhibition that is the important pro- 
cess in motor preparation (Gerilowsky \& Tsekov, 1975; Requin, 1969; Requin \& Paillard, 1971). Similarly, Requin et al. (1977) report a decrement after the early increase in amplitudes, which reaches its lowest value at 900 or $1,000 \mathrm{msec}$. This decline, interpreted as inhibition, seems to be a very general phenomenon: their $\mathrm{H}$ reflex amplitudes show the same time course during an ISI of $1 \mathrm{sec}$, with both agonistic and antagonistic movements of the foot. Because the decline of $\mathrm{H}$ reflex amplitudes also is present when the response is a hand movement, it must be a very generalized phenomenon, indeed.

The use of a larger ISI in our experiments reveals a new process after $1,000 \mathrm{msec}$, i.e., a steady increase of $\mathrm{H}$ reflex amplitudes. Although it may be hypothesized that the second increase might be related to motor preparation, again this increase is equally large, whether the calf muscles are involved in the response or not. At first glance, one may be inclined to relate the late increase during the ISI to the increase observed prior to a voluntary movement. Thus, PierrotDeseilligny, Lacert, and Cathala (1971) recorded an increase of monosynaptic reflex amplitudes in an involved leg $80 \mathrm{msec}$ prior to gastrocnemius-soleus contraction. Other data, pointing to a final increase of amplitudes before the movement have been reported by Coquery and Coulmance (1971), Gottlieb and Agarwal (1973a, 1973b), Kots (1969), and Mitchie et al. (1975). However, there is one important difference. The rise in amplitudes found in their studies is more closely time-locked to the movement than is the case in our experiments, for, in the latter case, it still takes 200-350 msec after the RS before the response is given. This indicates that after a general rise in excitability of the alpha motoneurons, new processes follow which are of final importance for the movement to be executed. Indeed, our most recent experiments show a selective increase of monosynaptic reflex amplitudes in the involved leg after the RS and before the movement (Brunia \& Haagh, Note 1). This presumably reflects the same process as that reported by the various authors mentioned above.

Thus, on the basis of the present data and the findings of others, it can be hypothesized that, using a RT paradigm with an ISI of $4 \mathrm{sec}$, an increase of reflex amplitudes can be recorded at three points in time: (1) an early increase, presumably related to the properties of the WS; (2) a late increase, which might be an aspecific element of motor preparation; and (3) a final increase, which may be recorded just before the onset of the movement.

\section{REFERENCE NOTE}

1. Brunia, C. H. M., \& Haagh, S. A. V. M. Manuscript in preparation. interval between auditory and stretching stimuli. Psychophysiology, 1971, 8, 504-508.

BRUNIA, C. H. M. What is wrong with legs in motorpreparation? In H. H. Kornhuber \& L. Deecke (Eds.), Motivation, motor and sensory processes of the brain: Electrical potentials, behavior and clinical use. Amsterdam: Elsevier, 1979.

Coquery, J. M., \& Coulmance, M. Variations d'amplitude des réflexes monosynaptiques avant un mouvement volontaire. Physiology \& Behavior, 1971, 6, 65-69.

Davis, C. M., \& BeAton, R. D. Facilitation and adaptation of the human quadriceps stretch reflex produced by auditory stimulation. Journal of Comparative and Physiological Psychology, 1968, 66, 483-487.

GAILlARD, A. Slow brain potentials preceding task performance. Soesterberg: Institute for Perception TNO, 1978.

Gerilowsky, L., \& Tsekov, T. S. Changes in the excitability of the segmental apparatus for reciprocal inhibition of agonist during a fixed waiting period. Agressologie, 1975, 16, 233-236.

Gottlieb, G. L., \& Agarwal, G. C. Modulation of postural reflexes by voluntary movement. 1. Modulation of the active limb. Journal of Neurology, Neurosurgery and Psychiatry, 1973, 36, 529-539. (a)

Gottlieb, G. L., \& Agarwal, G. C. Modulation of postural reflexes by voluntary movement. 2 . Modulation of the inactive limb. Journal of Neurology, Neurosurgery and Psychiatry, 1973, 36, 540-546. (b)

Kots, Y. A. M. Supraspinal control of the segmental centres of muscle antagonists in man. I. Reflex excitability of the motor neurones of muscle antagonists in the period of organization of voluntary movement. Biofizika, 1969, 14, 167-172.

Loveless, N. E. Event related brain potentials in selective response. Biological Psychology, 1977, 5, 135-149.

Loveless, N. E., \& SANFord, A. L. Slow potential correlates of preparatory set. Biological Psychology, 1974, 1, 303-314.

Mellvill Jones, G., Watt, D. G. D., \& Rossignol, S. Eight nerve contributions to the synthesis of locomotor control. In R. B. Stein, K. G. Pearson, R. S. Smith, \& J. B. Redford (Eds.), Control of posture and locomotion. New York: Plenum, 1973.

Mitchie, P. T., Clarke, A. M., Sinden, J. D., \& Glue, L. C. T. Lateral facilitation of Hoffmann reflexes prior to voluntary movement in a choice reaction time task. Applied Neurophysiology, 1975, 38, 191-196.

Papakostopoulos, D., \& Cooper, R. The contingent negative variation and the excitability of the spinal monosynaptic reflex. Journal of Neurology, Neurosurgery and Psychiatry, 1973, 6, 1003-1010.

Pierrot-Deseilligny, E., Lacert, P., \& Cathala, H. P. Amplitude et variabilité des réflexes monosynaptiques avant un mouvement volontaire. Physiology \& Behavior, 1971, 7, 495-508.

REQUIN, J. Some data on neurophysiological processes involved in the preparatory motor activity to reaction time performance. In W. G. Koster (Ed.), Attention and performance II. Amsterdam: North Holland, 1969.

Requin, J., Bonnet, M., \& Semjen, A. Is there a specificity in the supraspinal control of motor structures during preparation? In S. Dornič (Ed.), Attention and performance VI. Hillsdale, N.J: Erlbaum, 1977.

Requin, J., \& Paillard, J. Depression of monosynaptic reflexes as a specific aspect of preparatory motor set in visual reaction time. In Visual information processing and control of motor activity. Sofia: Bulgarian Academy of Sciences, 1971.

Rohrbaugh, J. W., Syndulko, K., \& Lindsley, D. B. Brain wave components of the contingent negative variation in humans. Science, 1976, 191, 1055-1057.

Semjen, A., Bonnet, M., \& Requin, J. Relation of the time course of Hoffmann reflexes and the foreperiod duration in a reaction time task. Physiology \& Behavior, 1973, 10, 1041-1050.

\section{REFERENCES}

BEALE, D. K. Facilitation of the knee jerk as a function of the
(Received for publication December 18, 1978; revision accepted August 31, 1979.) 